\title{
LA EMPATIA SEGÚN EDITH STEIN Y SUS APLICACIONES EN ENFERMERÍA EN EL CONTEXTO FAMILIAR
}

\author{
Amparo Nogales Espert \\ Facultad de Ciencias de la Salud \\ Universidad Rey Juan Carlos. Madrid
}

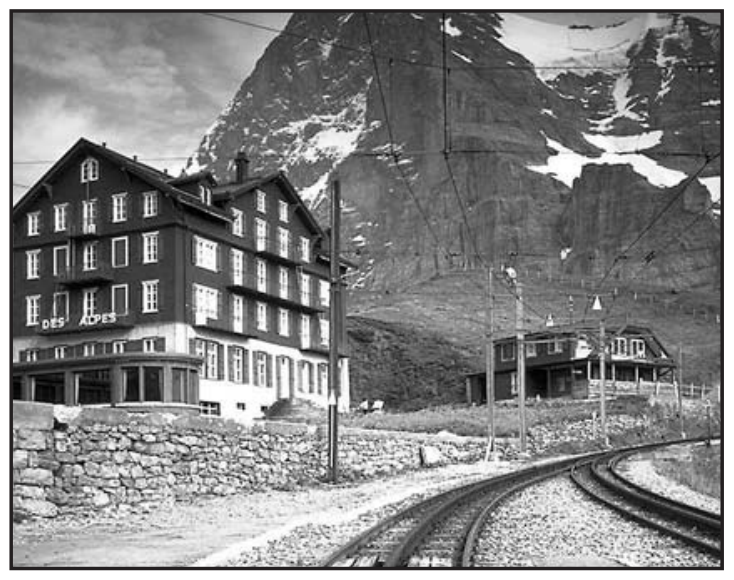

EMPATHY ACCORDING TO EDITH STEIN AND ITS APLICATIONS FOR NURSING IN THE FAMILY CONTEXT

\section{SUMMARY}

7 hrough a text analysis of Edith Stein's biography and work, we tried to draw those aspects of her personality that coincide with nursing values.

Key words: Observation, sensitivity, interest for human beings, afectiveness, reflection, human depth, search for the truth, empathic relation.

\section{A EMPATIA SEGUNDO EDITH STEIN E SUAS APLICAÇÕES NA ENFERMAGEM NO CONTEXTO FAMILIAR}

\section{RESUMO}

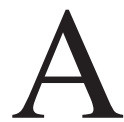

través de uma análise de textos sobre a biografia e a obra de Edith Stein, pretendese extrair aqueles aspectos de sua personalidade coincidentes com os valores da enfermagem.
Palavras-chave: Observação, sensibilidade, interesse pelo ser humano, afetividade, reflexão, profundidade humana, busca da verdade, relação de empatia.

\section{RESUMEN}

A través de un análisis de textos sobre la biografía y la obra de Edith Stein, se pretenden extraer aquellos aspectos de su personalidad coincidentes con los valores de la enfermería.

Palabras Clave: Observación, sensibilidad, interés por el ser humano, afectividad,

reflexión, profundidad humana, búsqueda de la verdad, relación de empatía.

\section{INTRODUCCIÓN}

Desde hace años me viene preocupando una idea respecto a los cuidados de enfermería y es la siguiente: la de si es posible realmente cuidar a los enfermos, a todos ellos, con una actitud afectiva y acogedora, manteniendo este talante de forma invariable durante todo el tiempo asistencial, a lo largo de meses y años de actividad profesional, y tanto en situaciones relajadas como en otras de mayor presión. O si, por el contrario, esta es solo una ilusión, un proyecto inalcanzable, que siempre estará presente como un reto al que poder llegar alguna vez.

En medio de estas dudas me encontré con la figura de una gran filósofa y fenomenóloga, Edith Stein, una de las mentes más claras que, en mi opinión, han iluminado el pensamiento en el siglo XX. Mi interés surgió ante el encuentro con una personalidad fascinante, dotada de un verdadero atractivo personal, y me interesó además por las características excepcionales de su biografía, y sobre todo 
porque dedicó su tesis doctoral al estudio de un tema que podía abrir caminos de reflexión al problema de la relación afectiva de la enfermera con el paciente. Edith Stein presentó su tesis doctoral en la Universidad de Friburgo en 1916, con el titulo "Sobre el problema de la empatía". Desde que conocí este dato, comprendí la importancia que para mí tenía el tratar de acercarme a esta personalidad y a esta obra, con la adecuada prudencia de alguien que se aproxima a la filosofía.

Mi primer encuentro con Edith Stein se produjo en el año 2005, cuando asistí en la Facultad de Teología “San Dámaso" en Madrid, a la Jornada sobre "Edith Stein y los Místicos Españoles".

El año 2006 asistí en el Centro Internacional de Estudios Teresiano-Sanjuanistas (CITES) de Ávila, del 15 al 19 de Mayo, al seminario "Vida, obras y pensamiento de Edith Stein".

Durante los cursos académicos 2006-2007 y 2007-2008, cursé en la Fundación Zubiri de Madrid los cursos de filosofía que estudian, entre otros fenomenólogos como Husserl, Heidegger, y Michel Henry, la obra de Edith Stein. Creo que seguir a esta pensadora, sin olvidar las dificultades del pensamiento fenomenológico, puede abrir nuevos horizontes a la enfermería en la búsqueda del conocimiento de las relaciones paciente-enfermera.

He dividido mi intervención en tres partes: en la primera realizaré una presentación resumida de la biografía de Edith Stein; en la segunda comentaremos sus principales experiencias de enfermería en la Cruz Roja, y en la tercera algunos aspectos destacables del primer capitulo de "Sobre el problema de la empatía".

\section{1.- RESUMEN BIOGRÁFICO}

¿Quién fue Edith Stein y donde reside el interés de su personalidad y su obra para la enfermería?.

1891.- Edith Stein nace en Breslau, Alemania, el 12 de Octubre, en una familia acomodada. Hija de padres judíos practicantes. El padre, Siegfried se dedicaba al negocio de la madera. La madre, Auguste Courant, era una mujer fuerte, emprendedora, dotada de gran personalidad.

1911.- Realiza el examen extraordinario para entrar en la universidad. Tiene 20 años. Comienza los estudios universitarios en germanística, historia, propedéutica filosófica y psicología en su ciudad, Breslau.

1912.- Tiene una crisis intelectual. Lee a Husserl, se interesa profundamente por su obra y decide cambiar de estudios y de universidad. Su madre la comprende y le presta apoyo económico.

1913.- Se traslada a la Universidad de Gotinga para seguir los estudios en la escuela fenomenológica de Husserl. Tiene 22 años. Conoce a Max Scheler, a Adolph Reinach y entra en contacto con el mundo de la fe.

1914.- Año en que prepara el examen de licenciatura y empieza a trabajar en la tesis doctoral con el tema de la empatía. Este mismo año estalla la primera Guerra Mundial. Alemania declara la guerra a Rusia y a Francia. Edith vuelve a su casa en Breslau.

1915.- En este mismo año vivirá una experiencia en cuidados de enfermería. Se alista como voluntaria asistente de enfermera de la Cruz Roja y trabaja durante 6 meses en el hospital austriaco de Mährisch-Weibkirchen en Chequia. Tiene 24 años.

1916.- En el mes de Agosto presenta su tesis doctoral en la Universidad de Friburgo, obteniendo la máxima calificación de "summa cum laude"; había trasladado sus estudios siguiendo al maestro Husserl, que también había cambiado a esta universidad. Tiene 25 años.

Se convierte en asistente de Husserl, encargándose como docente de introducir a los estudiantes en la fenomenología y, por otra parte, se dedicará a transcribir los manuscritos del maestro. Este trabajo como asistente de Husserl durará un año y medio.

1918.- Abandona voluntariamente el puesto de asistente de Husserl. A pesar del profundo respeto y cariño por el maestro, se da cuenta de que, en las condiciones en las que se encontraba, su futuro estaba limitado.

1919.- Husserl firma el certificado de idoneidad de Edith para presentarse a cátedra. 
Tiene 28 años. Intenta acceder a una cátedra en las universidades de Gotinga, Friburgo y Kiel. No llega a lograrlo debido a su condición de mujer.

Elabora trabajos científicos sobre política y estado.

Alemania firma el Tratado de Paz de Versalles.

Al iniciarse la republica de Weimar, la mujer consigue el derecho al voto y a la igualdad, pero alcanzar esa igualdad desde el punto de vista práctico será cosa distinta.

1921.- Permanece una temporada, desde el 25 de Mayo hasta Agosto en casa del matrimonio amigo Conrad-Martius en BadBergzabern. En Junio lee allí el "Libro de la vida" de Santa Teresa de Jesús, y este será el detonante que la empuja a decidirse definitivamente por el catolicismo. Tiene 30 años.

1922.- Recibe el bautismo el día 1 de Enero y la comunión en la iglesia de San Martín de Bad-Bergzabern. Toma el nombre de Edith Hedwig Teresa. En Febrero recibe la confirmación en la capilla del Palacio Episcopal de Espira.

1923.- Se traslada a Espira y trabaja como profesora de literatura y alemán en el instituto y Escuela de Magisterio de las Dominicas de esta ciudad.

1930.- Año intenso en charlas y conferencias:

- Nurenberg, 24 de Abril, conferencia:

"Fundamentos teóricos del aspecto social de la educación".

- Espira, 14 de Julio, charla: "La educación eucarística".

- Salzburgo (Austria), 1 de Septiembre, conferencia: "El ethos de la profesión femenina".

- Espira, 14 de Julio, charla: "Sobre la idea de la formación".

- Bendorg, 8 de Noviembre, conferencia: "Los fundamentos de la formación femenina".

- Heidelberg, 2 de Diciembre, conferencia: "El intelecto y los intelectuales".
1933.- Berlín, 2 al 5 de Enero imparte un curso sobre "La educación de la juventud a la luz de la fe católica".

- La situación política de Alemania se complica, especialmente para los judíos alemanes. El 30 de Enero Hitler sube al poder, y el 1 de Abril aparece una ley prohibiendo a los judíos desempeñar cargos públicos. Con ello se cerraban las puertas a Edith que se ve obligada a abandonar su trabajo docente. Como profesora, filósofa y conferenciante, su condición de judía cortaba su camino en todas direcciones. Comprende que ha llegado el momento de ingresar en el Carmelo.

- En su autobiografía Edith expresa su alegría por esta resolución de convertirse en religiosa; desde hacía tiempo era una idea muy meditada y ya decidida, de modo que ahora no aparece como la solución al problema planteado a su vida, sino como el momento adecuado para llevar a cabo su antigua decisión. Por ello todos sus pasos los dará, a partir de aquí, embargada de una inmensa alegría por ver llegado el momento de cumplir su deseo, solo ensombrecida por el gran dolor que esta decisión causaba en su madre.

- Con este objetivo de dar los primeros pasos hacia la profesión religiosa, el 15 de Julio marcha a Colonia para iniciar una experiencia de vida en el Carmelo, preparatoria de su entrada definitiva.

- Un mes después, el 15 de Agosto se dirige a su ciudad natal, Breslau, para estar con su familia y comunicarles la decisión de adoptar una vida religiosa. Permanece en casa un mes y medio. Su decisión es aceptada por los hermanos, no así por la madre, que se hunde en una gran tristeza. Edith siente profundamente ser la causa del dolor de la madre tan querida. 
- El 14 de Octubre, víspera de la festividad de Santa Teresa de Jesús Edith Stein ingresa en el Carmelo de Colonia. Tenía entonces 42 años.

1934.- Toma el hábito del Carmelo, orden religiosa de clausura con el nombre de Teresa Benedicta de la Cruz. Teresa por el nombre de la Santa fundadora a la que admiró desde q ue leyera por primera vez uno de sus libros. Benedicta por San Benito, fundador en Nursia, el año 525 , del monasterio y regla de vida para los monjes, "regula monachorum" que influiría decisivamente en las ordenes religiosas de Occidente; de la Cruz, porque desde mucho antes había ofrecido su persona para cargar con la cruz que se dejaba caer sobre el pueblo judío.

- Su vocación como filósofa, que había marcado toda su personalidad no se altera por ser religiosa. Y el Provincial de la Orden de los Carmelitas de Alemania, le concede permiso para continuar con la actividad filosófica en el convento, trabajando con la obra "Ser finito y ser eterno".

1938.- El día 19 de Abril los nazis llegan al convento con la intención de recoger los votos de las religiosas. Edith no puede votar por su condición de judía. Ya se sabe, por tanto, su lugar de residencia.

- Del 9 al 10 de Noviembre, estalla el odio antisemita en "la noche de los cristales rotos". La vida de Edith estaba en peligro si permanecía en Alemania; por ello se tomó la decisión de trasladarla a otro Carmelo fuera del país. El 31 de Diciembre marcha a Holanda, al Carmeno de de Echt, donde podrá sobrevivir solamente tres años y medio más.

- Las gestiones en ayuda de su hermana Rosa tienen éxito y el 1 de Julio ésta consigue llegar a Echt. En el convento profesa como Terciaria Carmelita y ocupa el puesto de portera y demandadera del mismo.
- Se inicia la Segunda Guerra mundial el 1 de Septiembre, con la invasión de Polonia por parte de Alemania.

- Una parte de la familia de Edith logra emigrar a Estados Unidos, Noruega y Colombia.

1940.- Día 10 de Mayo. Las tropas de Hitler invaden Holanda; el 14 de Mayo se produce la capitulación de Bélgica y los Países Bajos.

- La vida de las hermanas Stein corre peligro también en Holanda y comienzan las gestiones para su traslado a otro Carmelo fuera del país, en Le Pâquier, Suiza.

1941.- Día 13 de Enero. Los Obispos holandeses publican una carta pastoral en contra del Partido Nazi.

- La pasión por la búsqueda de la verdad y por dar salida a su pensamiento no decae en Edith, que continúa con su labor creadora, a pesar de los graves peligros en que se encuentra su propia familia y ella misma, y en Noviembre inicia el que sería su último trabajo, "La Ciencia de la Cruz". Será la segunda gran obra filosófica, que redactará en un tiempo record, pues nueve meses más tarde fue apresada por las SS.

- Mientras tanto el Carmelo de Echt continúa tramitando la documentación para el traslado de las dos hermanas a Suiza. Pero la puesta en regla de aquella, llegaría demasiado tarde.

1942.- Mes de Abril, la Gestapo registra a Edith y Rosa como judías. Esto significaba que aún permaneciendo dentro del convento, se hallaban perfectamente localizadas por la policía.

- El día 2 de Agosto Edith y su hermana Rosa son apresadas por las SS en el convento y llevadas al campo de concentración de Amesfoort en Holanda. Edith tenía 51 años. Solo una persona extraordinaria como Edith pudo vivir aquellos momentos de espanto con la entereza y dignidad 
que la acompañaron hasta el final, como pudo ir sabiéndose por unas y otras noticias de primera mano que posteriormente lograron recogerse.

- El 4 de Agosto, dos días después, las trasladan al campo de Westerbork, también en Holanda.

- El 7 de Agosto fueron deportadas al campo de exterminio de AuschwitzBirkenau.

- El 9 de Agosto llegan a Auschwitz y ese mismo día fuero asesinadas en la cámara de gas.

1962.- El día 4 de Enero se inicia de forma oficial el proceso de canonización eclesiástica por el Cardenal de Colonia.

1980.- La Conferencia Episcopal de Alemania pide a la Santa Sede en Roma, se inicie el proceso de beatificación.

1987.- Edith Stein es beatificada por el Papa Juan Pablo II el día 1 de Mayo, en el estadio de fútbol de Colonia.

1997.- El día 25 de Marzo se produce la aprobación por Juan Pablo II del milagro, que ha de ocurrir de forma imprescindible para que sea posible iniciar el proceso de canonización.

1998.- El día 11 de Octubre Edith Stein es canonizada santa en la Plaza de San Pedro de Roma por Juan Pablo II.

1999.- Día 1 de Octubre es declarada copatrona de Europa. Unos días después, el 9 de Octubre, la Asociación italiana de Psicólogos y Psiquiatras la declaran su patrona.

2002.- Aparece publicado en español el primer tomo de las Obras Completas de Santa Teresa Benedicta de la Cruz (STEIN Edith, 2002).

Este breve resumen no permite obtener con toda claridad un conocimiento de la persona de Edith Stein. Es imprescindible leer no solo su propia biografía, donde ella muestra su personalidad y la forma particular con que tomó posición ante cada circunstancia importante de su vida, las que fueron gratas y las otras negativas y difíciles de asumir. El lector se da cuenta de que se halla ante una inteligencia excepcional y ante una intelectual entregada a la investigación fenomenológica y, sobre todo, a la búsqueda de la verdad.

Pero aquí en su autobiografía aparece también la verdadera multitud de amistades y amigos en grados distintos con que contó, y la importancia de la amistad en su vida, que cultivó delicadamente a pesar de la distancia, lo que se aprecia con la lectura de las cartas, tanto las redactadas por ella misma como las que sus propios amigos le enviaron y se han publicado. Puede encontrarse a través de las mismas una gran sensibilidad y una extraordinaria capacidad de relación próxima y atrayente con los demás (STEIN Edith, 1998).

Debe leerse así mismo no solo lo que Edith cuenta, sino su vida escrita por otros, como la biografía de la Madre Teresa Renata Posselt, Madre de Novicias de la Orden del Carmelo de Colonia, que fue su propia maestra (POSELT, 2004), para tener la visión de los que conocieron su personalidad, inteligencia y su valor como persona. Y es necesario finalmente, para completar de forma más amplia la visión de quién fue Edith Stein, leer los escritos de su propia familia, como la obra de su sobrina, hija de su hermana y amiga Erna titulada "Mi tía Edith" (BATZDORF, 2001), donde se desvela otra faceta de su personalidad como miembro de una familia y de qué modo era comprendida y amada por sus seres queridos.

Edith Stein es interesante para la enfermería por su capacidad de penetración en la profundidad del ser humano, por sus estudios y penetrantes trabajos sobre el vivir humano, mostrados en su obra "Ser finito y ser eterno. Ensayo de una ascensión al

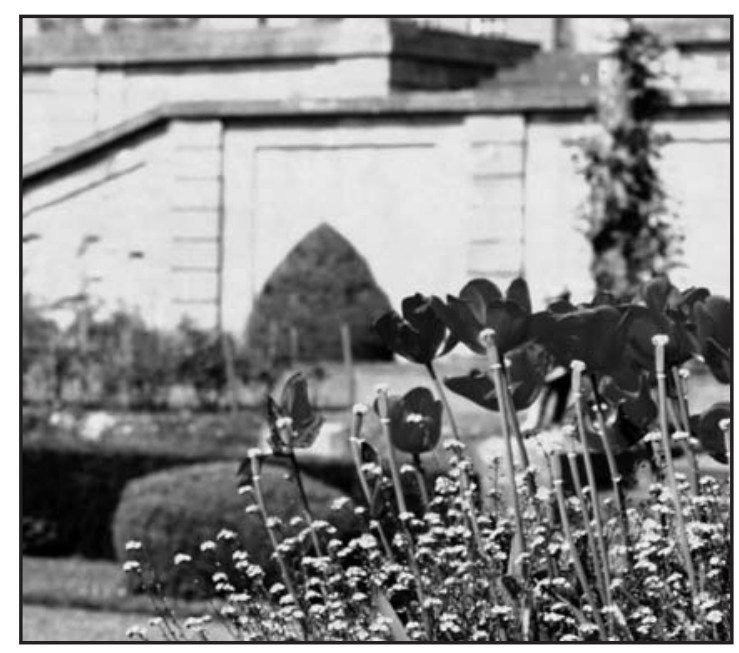


sentido del ser" y, especialmente, por su interés por las relaciones interpersonales y la forma en que se producen entre las personas, y cuando y como son o no posibles entre sí.

La preocupación por el tema de las relaciones humanas lo plasmó en la tesis doctoral titulada, como es sabido, "Sobre el problema de la empatía”, de modo que a esta temática dedicó una de sus primeras investigaciones filosóficas, llena de profundidad y penetración en las raíces y los caminos subterráneos seguidos por el ser humano para acercar su existencia a las otras vidas, para sentirse próximo o identificado con otros seres que suscitan interés e invitan a iniciar un acercamiento, cuyos pequeños aciertos producen grandes satisfacciones.

Interesa Edith Stein a la enfermería porque quien habla no es solamente una filósofa que podría encontrarse muy lejos de la profesión de enfermería, cuyas relaciones humanas se establecen en especial con personas del mundo de la enfermedad. Ella también dedicó una parte, aunque breve, de su vida al sufrimiento humano. Se sintió llamada a colaborar en la ayuda a los enfermos. Trabajó como enfermera de la Cruz Roja, durante la Primera Guerra Mundial, en un hospital de guerra, suspendiendo su proyecto personal e intelectual, para dedicarse a la ayuda de aquellos jóvenes soldados que habían entregado la vida por su país.

En el hospital austríaco de MährischWeibkirchen Edith entra en contacto con los enfermos, aprende a conocer las características del comportamiento de los pacientes afectos de tifus, su sintomatología, sus sufrimientos y cambios de carácter, vive de cerca el sentimiento de proximidad humana con algunos de ellos, siente la satisfacción del agradecimiento hacia su persona, y sobre todo, es testigo de la muerte de algunos de aquellos enfermos. Edith vivió la realidad de la vida del profesional de enfermería, y pudo comprender el hondo significado de la relación humana en estas circunstancias.

La relación entre su experiencia como enfermera y su obra "Sobre el problema de la empatía" se produce en el momento en que acaba de redactar el borrador de esta investigación. Cuando se encuentra en el hospital y uno de sus hermanos va a visitarla, pide a este que le traiga el cuaderno de trabajo. Y durante su tiempo libre, se dedica a repasar y analizar el borrador. Edith no cuenta si introdujo o no modificaciones en el mismo. Pero desde luego para nosotros es muy importante saber que fue repasado mientras vivía sus experiencias como enfermera y que estas, de uno u otro modo, dejaban en ella una huella que tenía que quedar forzosamente marcada en el escrito filosófico de la empatía.

En definitiva puede decirse aquí que habla de la empatía una persona que ha vivido experiencias de enfermería, que ha cuidado al ser humano y ha presenciado el dolor y la muerte en otras vidas a las que se entregó de llenó durante un tiempo de su existencia. No hay por tanto una desconexión entre empatía analizada filosóficamente y empatía como posibilidad de relación paciente-enfermera.

Para darnos cuenta de esto último efectuaremos un breve resumen de la experiencia que Edith Stein cuenta de su estancia como enfermera de la Cruz Roja y de su trabajo en un hospital.

\section{2.- EXPERIENCIA COMO AUXILIAR DE LA CRUZ ROJA:}

Año 1915, Primera Guerra Mundial. Edith se ofrece como voluntaria de la Cruz Roja. Es aceptada en un hospital de aislamiento en MährischWeibkirchen (ahora Hranice, Chequia). Este hospital atendía a soldados con enfermedades infecciosas: cólera, tifus, infecciones agudas, era por tanto, un centro de cuarentena. El conjunto arquitectónico correspondía a una academia militar habilitada como hospital para enfermos contagiosos, con 4000 camas dispuestas para evacuar a los enfermos del frente de los Cárpatos. Edith parte el 7 de Abril de 1915.

En su narración habla de buen número de enfermos a los que recuerda con sus nombres y el detalle de las experiencias de cuidados y de las vivencias compartidas con ellos. Los cuidados que prestaba eran en su mayoría, de los que llamaríamos poco gratos, pero en ningún momento aparece el menor asomo de desagrado o incomodidad al llevarlos a cabo: a un joven soldado, llamado Mario, que había perdido totalmente la voz y se hallaba imposibilitado para hablar, debía frecuentemente limpiarle con una gasa la boca de la que fluía una flema ensangrentada, y Edith solamente percibía el agradecimiento mostrado a través de la mirada. El equipo asistencial se permitía hablar 
durante el reconocimiento del enfermo con toda claridad como si el propio paciente no estuviera presente, pero Edith se daba cuenta de que el enfermo estaba atento y captaba perfectamente todo cuanto allí se hablaba; en general, aspectos del día a día que todos conocemos, y que para Edith no pasaban en modo alguno desapercibidos.

Pronto se dio cuenta Edith de la importancia de los cuidados de enfermería en el tratamiento de los enfermos de tifus: "Los médicos bien poco podían hacer contra esta enfermedad, pero mucho dependía del diligente cuidado de la enfermera. Nos sentíamos orgullosas de que se hubieran registrado pocas defunciones. Pero, a veces, se tenía que librar una dura batalla para arrancar a la muerte su víctima. La infección grave, y más aún cuando sobrevenía la inflamación pulmonar, afectaba con frecuencia al corazón, de tal suerte que amenazaba el paro cardíaco". En los casos más graves debían duplicar la vigilancia; algunos enfermos precisaban como tratamiento una inyección de alcanfor cada hora, o bien vigilar constantemente que mantuviesen un ayuno riguroso, cosa difícil de conseguir, pues algunos de ellos esquivaban esta prescripción; en otros casos más graves había que administrar pequeñas cucharadas de huevo con coñac.

Con claridad Edith manifiesta que su mayor gusto era el trato con los enfermos, a pesar de las dificultades de comunicación, puesto que los soldados hospitalizados pertenecían a todas las nacionalidades de la monarquía austro-húngara: alemanes, checos, eslovacos, eslovenos, polacos, rutenos, húngaros, rumanos, italianos, incluso gitanos. Dice así: "Con mucho, lo que más me gustaba era la relación con el paciente; aunque esto ofrecía algunas dificultades... con unas cuantas expresiones y algo de mímica salía una de apuros”.

Habla también del estado de postración de la mayoría de ellos, que no les dejaba energía apenas para comunicarse: "Más dificultades habría habido si los pacientes hubieran tenido necesidad de entretenerse conversando, pero la mayoría se encontraba en una situación en la que no estaba para ello. Su total desamparo y necesidad de cuidado, me hacía más amable el trabajo".

Deja traslucir igualmente el lógico cansancio derivado del cuidado de los enfermos: "También yo me acostumbré pronto al café fuerte y a los cigarrillos. Los nervios exigían algún estimulante cuando se regresaba de la sala de los enfermos".

En sus cuidados de enfermería narra la experiencia de la muerte de dos enfermos. Su conducta es la de una intelectual que se comporta serenamente, cumpliendo con las funciones que debía desempeñar en cada momento; no hay muestras, al parecer, de alteración afectiva, y por ello preguntamos: ¿pudo influir en ello su estudio en profundidad de la empatía, su saber sobre el verdadero sentido de la mima, de sus componentes y significado?. No lo sabemos. Solo expresa cómo se sintió implicada afectivamente en uno de los casos:

Una compañera " me vino a buscar llena de miedo en la primera noche, para atender a un moribundo. El pobrecillo no podía en su agonía hacerse entender. Se trataba de un alemán, y ella no entendía ni una sola palabra. Yo le dije que avisase rápidamente al médico que estaba al lado también de guardia, y entre tanto le puse una inyección. El médico vino enseguida pero no había nada que hacer. Solo pudo esperar la muerte y extender el certificado".

"Era la primera vez que yo veía morir a alguien. La segunda defunción fue en nuestra sala... Al llegar me indicaron que había ingresado un moribundo... Me indicaron que le pusiese cada hora una inyección de alcanfor. Muchas noches yo prolongaba así la chispita de vida hasta la mañana siguiente. Era un hombre alto y fuerte. Yacía inmóvil y sin conocimiento; había llegado ya así. Nadie lo vio con los ojos abiertos ni le oyó una palabra. La última noche le había puesto algunas inyecciones, y entre tanto oía desde mi sitio la respiración; hubo un momento en el que cesó. Me acerqué a su cama: el corazón no palpitaba más". No introduce aquí ninguna expresión respecto al impacto que le produjo, o si aquella muerte presenciada ocasionó en ella un estremecimiento interno, sino que prosigue de este modo:

"Entonces tuve que hacer lo que se nos había indicado en aquellos casos: recoger las pocas cosas personales que tenía allí para dárselas a la oficina militar; llamar al médico para el certificado de defunción; ir a la guardia de la puerta y pedir hombres para que se lo llevaran en una camilla; finalmente quitar la ropa de la cama".

Fue en aquél momento cuando se sintió en verdad afectada: "Cuando ordené sus cosas, se cayó 
fuera de la agenda del difunto una tarjetita: contenía una oración para que se le conservase la vida y que su mujer le había dado. Esto me partió el alma. Comprendí, justo ahora, lo que humanamente significaba aquella muerte. Pero yo no podía quedarme allí. Reaccioné para ir a buscar al médico..."

La entrega de Edith a los enfermos queda constantemente plasmada en su narración. Uno de los apartados lo titula "Pensando en los enfermos", y lo reproducimos por su valor testimonial, que muestra a una enfermera verdaderamente entregada a su trabajo, con el único interés de ayudar a los enfermos a sentirse mejor:

"El mes de Agosto de 1915 que lo pasé en esta sección fue el más difícil de mi tiempo de enfermera.... Ahora tenía de nuevo una agotadora actividad de asistencia a personas muy necesitadas, como a mí me gustaba. En la habitación grande había 9 camas. Los enfermos aquí instalados, tenían casi todos roturas complicadas de fémur y portaban fuertes vendajes. Mientras estaban en el quirófano grande para el cambio de vendajes, yo debía hacer rápidamente sus camas $\mathrm{y}$, por supuesto, con mucho esmero, pues los enfermos habían de estar rígidos e inmóviles. Cuando volvían había que tensar el peso en un muslo vendado hasta conseguir que la pierna tomase la posición en que menos dolor produjese. Cada movimiento a lo largo del día, hacía necesaria una variación de la pesa. Por la tarde iba de cama en cama, y daba fricciones de alcohol y polvos a cada uno en el sitio donde el cuerpo sufría más presión, para impedir las ulceraciones. Un suboficial alemán, que nos daba mucho trabajo por su descontento y criticonería dijo: "La enfermera tiene más trabajo con nosotros que una madre con 9 hijos".

Con esta secuencia de exposiciones Edith va mostrando su entrega total al servicio de los enfermos; se nota que había hecho un paréntesis en su vida de filósofa, para interesarse intensamente por todo aquello que pudiera realizar en ayuda de los enfermos, dejando en segundo plano, incluso su preocupación por sí misma. Esta entrega sin condiciones le producía gran cansancio físico, pero sin duda, notables motivos de satisfacción al comprobar la mejoría, o las respuestas afectivas de los enfermos, que no pasaban desapercibidas para ella, sino al contrario, le producían especial alegría:

"Como estaba casi todo el tiempo moviéndo- me, por la noche apenas me tenía en pié. Algunas veces me iba rápidamente a nuestro cuarto $\mathrm{y}$ Alwine u otra alma compasiva me llevaba la cena, y así me ahorraba un rato de estar de pie. Era un alivio deslizarme en la cama y dejar descansar los fatigados pies. Al menos los pies, pues no podía dormirme enseguida. Me sentaba medio dormida en la litera, mirando por la gran ventana al Beczwa y el dorso de la colina en cuyo final estaba Helfenstein. Era una vista deliciosa cuando salía la luna. Pero yo pensaba en mis enfermos y me sentía feliz cuando llegaba la mañana y comprobaba que no les faltaba nada".

Llegó el inevitable cansancio y Edith pidió, como era habitual, un permiso para ir a casa el $1 \mathrm{de}$ Septiembre. La enfermera jefe..."no puso ningún inconveniente y ni siquiera me fijó el plazo de dos semanas de permiso, sino que dejó a mi elección si quería volver y cuándo. Yo le rogué me llamase cuando fuera necesaria mi ayuda".

La espera del regreso al hospital quedó definitivamente resuelta de la siguiente manera: "No había recibido aún llamada alguna para volver a Weibkirchen. En su lugar (todavía en Octubre) me encontré a Suse Mugdan, que me dio la noticia de que el hospital se había cerrado. Desde que Galicia había sido liberada de rusos, Weibkirchen ya no estaba en la retaguardia y el edificio tuvo que volver a su función anterior. Suse y yo nos volvimos a poner a disposición de la Cruz Roja para ser destinadas a otro sitio, pero no recibimos ninguna convocatoria más" (STEIN, 2002).

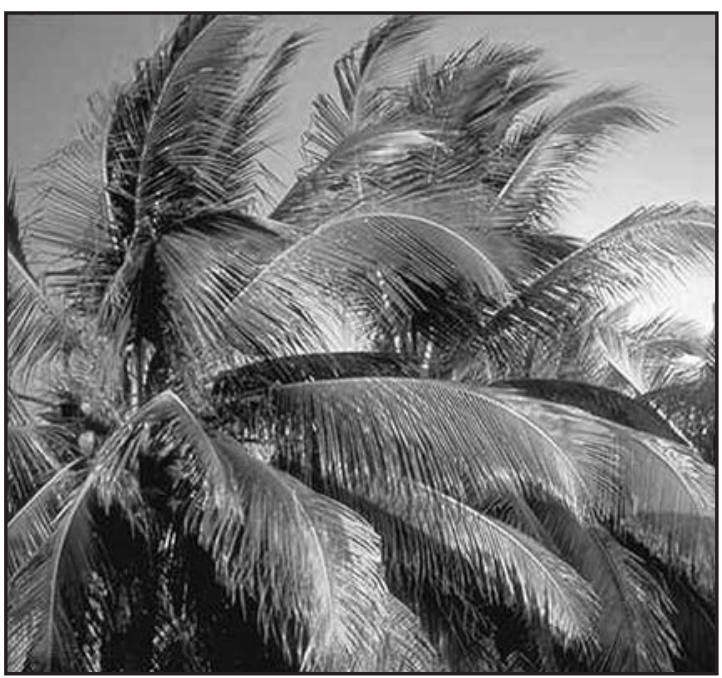




\section{3.- SOBRE EL PROBLEMA DE LA EMPATÍA}

Parece indudable que la experiencia hospitalaria de la Cruz Roja dejó marcada una honda huella en Edith Stein, que vio allí extinguirse la vida en varias ocasiones; pudo ver el momento en que se agota el espíritu y el cuerpo humano pierde la vida; presenció lo que es dejar la vida y convertirse el cuerpo inerte en materia que ya no está viva; vivió este sinsentido y experimentó, por otra parte, otras hondas vivencias, la amistad y sus profundas satisfacciones. Vivió hasta la extenuación una entrega total a los enfermos y pudo sentir la impresión reconfortante de ver mejorar a personas enfermas como resultado de su actuación directa y ver animarse a enfermos graves con sus palabras y cuidados.

Edith no dice que introdujera modificaciones en su tesis como resultado de las vivencias experimentadas en los 6 meses de trabajo de cuidar enfermos. Pero esto no es lo importante. Lo que nos importa es que en la misma persona de Edith coinciden los trabajos de investigación sobre empatía y las vivencias y relaciones especiales con pacientes y personal de las profesiones sanitarias.

Estoy convencida de la relación que pudo haber entre la investigación filosófica de Edith Stein en su tesis doctoral sobre la empatía, y el trabajo de cuidar, con las vivencias y experiencias íntimas de contacto personal, que Edith vivió con sus pacientes durante el tiempo transcurrido como cuidadora de los soldados del frente de guerra en un hospital de la Cruz Roja.

Por ello en mi opinión tiene especial importancia la lectura de este texto que Edith Stein escribió sobre la empatía y tratar de ponerlo en relación con la experiencia de cuidar del profesional sanitario.

Edith Stein no fue indiferente a las palabras de agradecimiento, a las sonrisas agradecidas que recibió; se sintió implicada en la preocupación por la gravedad de sus pacientes, y dejó traslucir su sobrecogimiento ante el dolor y la muerte. Actuó entregándose a fondo, olvidándose por completo de sí misa, para darse plenamente, con toda intensidad, a los requerimientos de las personas que la necesitaban, sin reparar en esfuerzo alguno. ¿Qué era todo ello?. Actos de empatía, que Edith analizó fenomenológicamente en su investigación doctoral. Por ello considero tan interesante su lectura, leyendo con detalle cuanto en ella se dice sobre el problema de la empatía, de manera que podamos obtener nuevas y más amplias visiones para comprender las relaciones de los profesionales que cuidan, con sus enfermos.

Como es sabido el titulo "Sobre el problema de la empatía" (STEIN Edith, 2004) es el que Edith Stein puso a su tesis doctoral. Pretendemos realizar una aproximación a la primera parte de esta obra, atraídos por la persona y el título de la misma, para tratar de encontrar en su lectura aquellos aspectos que nos sirvan para ver con más claridad en qué consiste la empatía aplicada al cuidado de los enfermos en la profesión de enfermería.

La propia Edith Stein imprimió por su cuenta la obra, pero no lo hizo en su totalidad, sino que publicó la segunda, tercera y cuarta parte. La primera parte, según indica la autora, trata de la historia de la empatía, e informa así mismo que excluyó de la impresión los aspectos sociales, éticos y estéticos de la empatía. Lo que nos queda por tanto, es el trabajo sobre la esencia de los actos de empatía que es la segunda parte, la tercera que trata de la constitución del individuo psicofísico y la cuarta que versa sobre la empatía en cuanto comprensión de personas racionales.

Por cuestiones de espacio nos limitamos a iniciar la primera parte titulada "La esencia de los actos de empatía". La metodología utilizada consiste en realizar un comentario introductorio para situar la obra; enunciar el índice inicial del capítulo estudiado y a continuación iremos presentando la materia que en nuestra opinión proporciona información aplicable a enfermería, añadiendo el comentario que esta indagación nos sugiere.

\section{Comentario introductorio}

Por lo que hemos conocido de Edith Stein sabemos de su delicada capacidad de observación y de su disposición para analizar introspectivamente cuantas vivencias le proporcionaba el entorno, así como los grandes resultados intersubjetivos que obtenía de sus relaciones personales.

Quizá esta predisposición al análisis profundo en torno al ser humano y a su capacidad de relación la llevó primero a la lectura de la obra de Edmund Husserl, "Investigaciones lógicas" en 1912 y, como consecuencia, a abandonar los estudios de psicología empírica y dedicarse a la fenomenología bajo el magisterio del maestro Husserl. Para 
ello tuvo que dejar su ciudad natal, Breslau y trasladarse a Gotinga, donde comenzaba a formarse la escuela fenomenológica. Pero el estudio de la empatía concretamente le vino sugerido por la obra de su maestro "Ideas para una fenomenología pura y una filosofía fenomenológica", donde Husserl hace referencia a la empatía y a su importancia en las relaciones personales. Esto llevó a Edith a interesarse por el estudio de esta vivencia particular común al ser humano, que hace que dos personas entren en una especial relación recíproca.

\section{La esencia de los actos de empatía}

El concepto de empatía de Edth Stein es el de "aprehensión de las vivencias ajenas, apercibimiento del vivenciar de otro". Ella analiza desde perspectivas diversas cómo se hace posible esto y encontrará matices diferenciales que la ayudarán a distinguir entre empatizar, consentir y sentir a una.

La autora habla de "captar en mí algo trascendente a mí como son las vivencias de otros", como lo esencial de la empatía, y dicho esto trata de llegar al fondo de los sujetos que participan en esta relación, buscando cual es su estructura, y a los que finalmente definirá como "individuos psicofísicos y personas espirituales", es decir, cuerpo vivo en unidad sustancial con el alma o psique.

Está indicando, ya desde el principio, esa cualidad humana de percibir en sí misma vivencias que no son propias, sino que trascienden a uno mismo y proceden de otro sujeto que no es el yo. Algo que la enfermera vive constantemente, y que ahora vemos no como una posibilidad, sino como una realidad que se da en la normalidad de la vida.

Desde esta visión la empatía es un "acto espiritual que tiene su condición de posibilidad en el espíritu del sujeto". De esta forma la experiencia empática es posible por los elementos que en su conjunto constituyen la persona propia y la ajena, cuerpo, alma o espíritu y por las posibilidades de comportamiento que ofrece el engranaje de estos elementos.

La autora se ocupa, así mismo de dos grandes temas: causalidad y motivación, que subyacen, por otra parte, en su particularidad de persona formada intelectualmente y en la manera con que afronta las diferentes circunstancias vitales que irán dando forma a su vida: la búsqueda de la verdad la lleva al estudio de la fenomenología por una parte, y al cristianismo como religión en la que orientar la vida, por otra; a encontrar al ser humano en su esencia constitutiva y a prestarle su ayuda; esto la condujo a la Cruz Roja, en apoyo de los soldados heridos, y a una profunda motivación por servirles en todo aquello que estuviera en sus manos, y este objetivo la convirtió en una total enfermera ejerciendo vivamente la excelencia en los cuidados particulares de sus enfermos.

La empatía enfocada desde un nivel personal, sentida desde la propia individualidad, permite a la autora hablar de procesos interiores, y en consecuencia, estos procesos vendrán a constituir vivencias supraindividuales, las cuales aportan una excepcional riqueza interior a la persona que experimenta en sí misma estas vivencias.

A continuación presenta Edith lo que es la empatía y seguidamente aclara que lo que ofrece en este trabajo no termina por agotar el tema, sino que pretende mostrar justamente, lo que aún queda por investigar sobre el mismo. Dice así: "Como problema fundamental reconocí la cuestión de la empatía como experiencia de sujetos ajenos y de su vivencia. Esta cuestión es examinada en las exposiciones siguientes. Soy muy consciente a este respecto de que los resultados positivos a los que llego solo son una pequeña contribución para presentar lo que aquí queda por hacer".

Es decir que la empatía es, finalmente, la vivencia de experiencias de sujetos ajenos, la vivencia de experiencias de otros. Vivencias de experiencias de otros que abren en uno horizontes distintos al que es propiamente personal. Además la empatía es presentada como problema, sin que se añada una razón justificativa. Veremos, en un estudio más avanzado, si Edith Stein aclara en algún momento este extremo.

Preguntamos también: ¿vivencia es lo mismo que experiencia?. ¿Se pueden vivir con idéntica fuerza real las experiencias de los otros que las propias?. ¿Se experimentan también las experiencias de los otros, o las experiencias solo pueden ser propias?.

El Diccionario de la Real Academia española de la Lengua dice de experiencia: "Hecho de haber sentido, conocido o presenciado alguien algo. Práctica prolongada que proporciona conocimiento o habilidad para hacer algo. Conocimiento de la vida adquirido por las circunstancias o situaciones 
vividas. Circunstancia o acontecimiento vivido por una persona".

La vivencia es: "Hecho de experimentar algo y su contenido. Hecho de vivir o estar vivo".

Así pues según el diccionario experimentar y vivenciar consisten ambas en vivir una experiencia. A mi me parece, sin embargo, que Edith Stein sí que establece una diferenciación, y llama experiencia a aquello que uno vive personalmente, es decir, en su propia persona y vivencia a la aproximación de uno mismo a la experiencia de otro, y cuando ello se realiza vivamente y con plena consciencia, le llama empatía. Creo que la empatía es la aproximación máxima de uno a las experiencias de otro que incluye una gran comprensión de lo que ocurre en el otro sujeto. Pero que la empatía, aún reconociéndole varios grados y situándose en el de mayor intensidad, nunca puede llegar a ser igual que la propia experiencia, o convertirse en la misma experiencia personal del sujeto que realmente vive un hecho experiencial.

Si esto fuera así, quizás estaría apuntando hacia un explicación del por qué es posible que una enfermera pueda empatizar con sus pacientes, y vivenciar las experiencias de aquellos en un acto de comprensión del sufrimiento, del dolor etc., sin que esto termine por agotar el propio equilibrio personal, sino que, por el contrario, pueda convertir la personalidad enfermera en un ser profundamente conocedor de los matices que constituyen y diferencian el alma humana.

El primer capítulo de "Sobre el problema de la empatía" se titula "La esencia de los actos de empatía" y se compone de los dos primeros apartados siguientes:

1.- El método de la investigación

2.- Descripción de la empatía en comparación con otros actos:
a) Percepción externa y empatía
b) Originariedad y no originariedad
c) Recuerdo, espera, fantasía y empatía

\section{1.- El método de la investigación}

El discurso de la empatía parte de unos presupuestos básicos: "Nos están dados sujetos ajenos y sus vivencias", y a lo que Edith Stein quiere llegar es a desvelar el desarrollo de este proceso, al fundamento de esta forma de darse y de sus efectos, llegando hasta su esencia a través de la reducción fenomenológica.

Para nosotros desde la enfermería se da una evidencia que ya no abandonaremos, la constitución de la persona propia y la ajena de un yo que es, al mismo tiempo, cuerpo, alma y espíritu. De modo que lo que tengo frente a mí no es solo la corporeidad que contemplo, sino que veo en su conjunto además, alma y espíritu.

Creo que es un buen comienzo para enfermería analizar este punto de partida: que en nuestro trabajo nos están dados, de forma inevitable, sujetos ajenos en unidad de su triple composición y de sus propias vivencias, en un marco en que las vivencias de aquellos son, primordialmente, experiencias negativas de enfermedad. Y estas están inevitablemente ahí, ante nosotras.

La fenomenología tiene como objetivo "la clarificación y fundamentación última de todo conocimiento". Para ello no hace uso de ninguna ciencia, ni se apoya en la experiencia natural, sino que se fundamenta en sí misma.

Lo que no puede excluirse de la investigación fenomenológica es lo que realmente existe fuera de toda duda, la propia vivencia de las cosas; el objeto que se me da en series de percepciones distintas, todas ellas unidas en su carácter total e inalterado frente a mí, como objeto de consideración.

Pero no se trata de aprehender los fenómenos singulares y hacerlos presentes, sino de penetrar en su realidad y llegar hasta su propia esencia. Si cada fenómeno tiene en su base una esencia propia, la fenomenología de la percepción debe ir más allá del describir para indagar lo que realmente es "percepción en general".

Ocurre que el sujeto que vivencia, que soy yo, el mismo que ve al mundo y a su propia persona como un fenómeno dentro de él, estoy, yo mismo, en el propio vivenciar de una forma indiscutible.

Aplicando esta consideración al mundo en el que me encuentro, veo que no es solamente un mundo de cuerpos físicos, sino que, además de mí, hay también en él sujetos con sus propias vivencias, las de ellos, pero yo sé que está ahí ese otro vivenciar.

En el mundo de la experiencia personal el individuo psicofísico se diferencia claramente de la cosa física, pero este individuo se da como ser vivo sentiente, poseedor de un yo que padece, quiere y 
piensa, y ese cuerpo vivo no solo está situado en mi mundo, sino que aparece formando parte de él, en relación directa conmigo. De modo que en la conciencia se constituye todo aquello que me aparece del otro, más allá de su cuerpo físico y de lo que se da en la percepción externa.

Ese individuo poseedor de un yo, está llenando mi mundo del trabajo bien como enfermo o como profesional de mi equipo y me es imposible prescindir de su presencia porque forma parte del mundo al que pertenezco. Puedo forzar la realidad y dejarlo aislado, excluirlo de mi entorno. Pero el resultado es el de una realidad forzada, parasitaria y oscura, que finamente distorsiona la esencia del trabajo de enfermera, cuyo objetivo fundamental es justamente lo opuesto, velar por el bien de los otros.

El darse del otro me permite descubrir no solo lo que expresa a través del semblante en palabras y gestos, sino lo que oculta detrás de su expresión (uno puede mostrar el semblante triste y en realidad no estar afligido). De manera que los diferentes modos de darse responden a fundamentaciones distintas que pueden investigarse.

En una consideración de mayor profundidad Edith Stein recoge estos datos del vivenciar ajeno y los remite a una forma de aprehensión distinta, que diferencia dándole el nombre de empatía. Comprender y describir estos actos de empatía será su objetivo.

\section{2.- Descripción de la empatía en comparación con otros actos}

La empatía queda diferenciada cuando la comparamos con otros actos de la conciencia. Para señalar la esencia del acto empático Edith Stein pone el ejemplo del amigo que viene hacia mí y me dice que ha perdido a su hermano y "yo noto ese dolor”. “QQué es este notar?”. Lo que interesa ahora a la autora es, precisamente, este notar, no los datos que me hacen sentirlo como la cara pálida, la voz alterada, o las propias palabras de dolor. Lo que le interesa aquí es "el notar mismo" y no el camino por el que se ha llegado hasta él.

Como enfermeras no debemos dejar pasar por alto este dato, pues en la práctica constantemente notamos los signos de dolor en los enfermos, y solemos frecuentemente apartarlos de nosotras, como si no nos diéramos cuenta, Creo, por el contrario, que el acto empático no termina en el notar, sino que este apercibimiento es solo la primera parte, y que la empatía tiene una segunda parte que finaliza con mi respuesta, que ha de dejarse ver, es decir, que consiste en demostrar al otro que me he dado cuenta y que me hago cargo, que comprendo, y participo de ese dolor.

\section{a) Percepción externa y empatía}

Para Edith Stein "yo no tengo ninguna percepción externa del dolor", pues la percepción externa ocurre cuando se dan a un mismo tiempo el hecho en sí (en este caso el dolor) y la percepción de aquél. El dolor no se me da de la misma manera que percibo una cosa, porque el dolor no es cosa, ni siquiera cuando lo capto en los gestos de la otra persona.

Puedo traer al "dárseme originario", a la percepción del ahora mismo, otras formas de ver aquello que percibo, otros lados de aquella percepción. Dice la autora: "Puedo contemplar por cuantos lados quiera el semblante conmovido de dolor, mejor dicho: la torsión de la cara que empáticamente aprehendo como semblante conmovido de dolor". Como vemos, para Edith Stein en la captación e interpretación del gesto como de dolor, ya está presente la empatía. Pero encuentro que esta captación e interpretación requieren algo previo para hacerse posibles y es la actitud del sujeto que percibe. Sin una actitud atenta a lo que ocurre en el otro, y bien predispuesta a captar la información que sale de aquél, esta información será ignorada, desechada o no valorada y por tanto, se le dará una respuesta inapropiada, o bien, no tendrá respuesta. Hace falta la disposición del otro.

Pero la autora continúa por otro camino para dar respuesta al epígrafe "percepción externa y empatía", diciendo: "la empatía no tiene el carácter de percepción externa, pero tiene algo en común con ella". Percepción externa sería, creo yo, ver el rostro dolorido, lo que se completa, para ser empatía, con la interpretación, el entender el por qué de ese gesto, y para ello es necesaria la intención de comprensión.

\section{b) Originariedad y no originariedad}

Para la autora "aún hay algo del mundo externo que nos está dado originariamente. Dándose originariamente (continúa), está también la ideación en la que aprehendemos intuitivamente rela- 


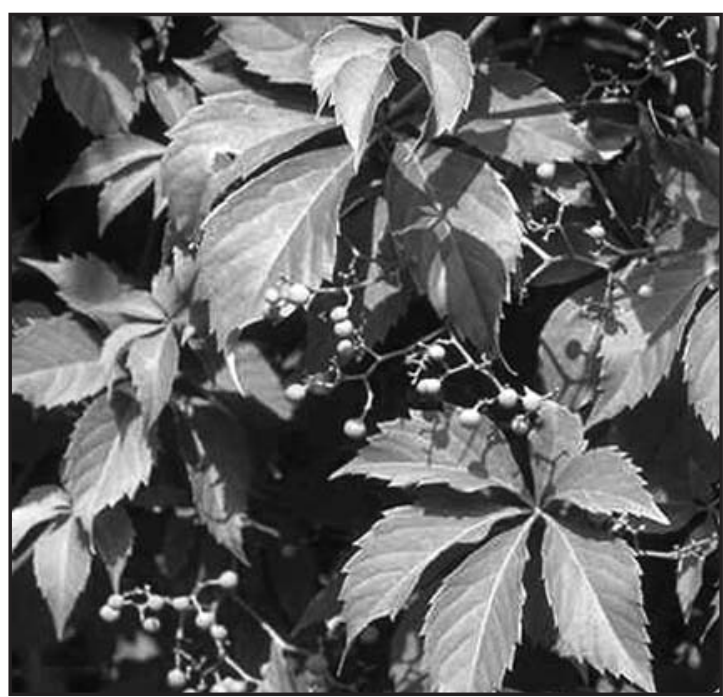

ciones esenciales, la intelección de un axioma geométrico o la captación de un valor, están dándose originariamente; por último y ante todo, tienen carácter de originariedad nuestras propias vivencias tal como vienen a darse en la reflexión". Es decir, tiene originariedad lo que es propiamente nuestro, una vivencia, una experiencia y además aquello que captamos como de primera mano, por intuición, como acabamos de ver en los ejemplos, un valor, o la comprensión de un problema matemático.

Naturalmente la empatía no es "una ideación trivial", es una aprehensión de lo que ocurre en el otro, de la vivencia del otro. La empatía puede ser la base para llegar a adquirir un conocimiento esencial de las vivencias que me son ajenas.

Entonces pregunta la autora: “¿posee la empatía la originariedad del vivenciar propio?”. Y continúa con la búsqueda de una distinción mayor del sentido de la originariedad, diciendo: "originarias son todas las vivencias propias presentes como tales. Pero no todas las vivencias están dándose originariamente, no todas son originarias según su contenido. El recuerdo, la espera, la fantasía, tienen su objeto no como propiamente presentes ante sí, sino que solo lo presentifican. Y el carácter de la presentificación es un momento esencial inmanente a estos actos, no una determinación obtenida de los objetos".

Para cada vivencia, por tanto, existe la posibilidad de un darse originario. Pero también existe la posibilidad de darse ciertas vivencias de un modo no originario como el recuerdo, la espera, la fantasía. Seguidamente Edith Stein vuelve a plantear la misma pregunta que, curiosamente, deja aquí abierta, sin añadir respuesta alguna: “¿conviene la originariedad a la empatía?. ¿En qué sentido?.

Queda formulada la pregunta (que después responderá), quizá para que agreguemos la respuesta. Creo que la originariedad no conviene a la empatía, en el sentido de que la empatía es la aprehensión en mí de las vivencias de un sujeto distinto al yo, y pienso que, aunque se produzca una captación y un cosentir con el otro, la originariedad está siempre en la vivencia de aquél, porque en él reside la fuente de dicha vivencia y no en mí y, por tanto, la intensidad primaria de la misma.

\section{c) Recuerdo, espera, fantasía y empatía}

Edith Stein encuentra una semejanza entre los actos de empatía y los actos en los que aquello que uno vivencia no está dado originariamente, no nace en sí mismo y en ese instante. Y pone como ejemplo el recuerdo de una alegría que es, por una parte originario porque presentifica aquello que fue la alegría, y por otra no es originario, porque si bien la alegría "estuvo viva una vez", ahora no lo está en términos reales. Aunque puede recordarse con tal intensidad como si fuera real, no lo es.

El yo del pasado no es el yo de ahora, sino que son dos yos situados frente a frente.

Puede suceder otra cosa en el recuerdo según la autora: "es posible que yo me remonte expresamente a aquel punto temporal en la corriente continua de vivencias y deje despertarse otra vez la secuencia de vivencias de entonces, viviendo en la vivencia recordada en vez de volverme a ella como objeto: desde luego que el recuerdo es, en todo caso, presentificación, su sujeto es no originario a diferencia del que realiza el recuerdo", que soy yo.

El caso de la espera es semejante al del recuerdo. Aquello que espero (una persona, un suceso, un regalo) no es originario, sino que está presentificado en una espera más o menos significativa deseada, ardiente, o también, temerosa o temida.

Respecto a la fantasía dice la autora que "el yo que crea el mundo de la fantasía es originario, mientras que el yo que vive en él, es no originario. Y las vivencias fantásticas están caracterizadas frente a las recordadas por el hecho de que no se 




dan como presentificaciones reales, sino como forma no originaria de vivencias presentes".

Dice así mismo: "También es posible que mirando dentro del reino de la fantasía (como también del recuerdo y de la espera) me encuentre a mí mismo dentro, es decir a un yo que reconozco como a mí; es como si viese mi imagen en el espejo".

Y llegando a la empatía Edith Stein la refiere, por una pare, como un acto originario, como vivencia presente (porque aprehendemos en el presente lo que es presente del otro), pero por otra parte, no originario por su contenido. Contenido que puede presentarse como vivencia que, como antes hemos dicho, puede ser en forma de recuerdo, espera, fantasía. "Cuando la vivencia aparece ante mí de golpe, está ante mí como objeto, por ejemplo, la tristeza que leo en la cara de otros", pero mientras aclaro mas detalles, ella (la tristeza)", ya no es objeto, me ha transferido hacia dentro de sí, ya no estoy vuelto hacia ella, sino vuelto en ella hacia su objeto, estoy en su lugar".

No está muy claro si Edith Stein se refiere a que se produce una identificación total entre mi vivencia y la vivencia del otro que he aprehendido en un acto de empatía. Pero aunque así fuera, sigo diciendo que mi vivencia es no originaria, y que por ello, es menos potente, menos enérgica que la originaria vivida por el otro sujeto.

Esto no quiere decir que el sujeto del que parte la vivencia originaria no se sienta gratificado al darse cuenta del acto de empatía que está ocurriendo. Lo que quiero decir es que quizás aquí encontramos la explicación de que, al no ser originaria la empatía, no produce quizás el mismo desgaste emocional que si lo fuera, y que por tanto, en relación con la enfermería, ello justificaría la posibilidad para la enfermera de empatizar con experiencias de sufrimiento y dolor de múltiples seres, sin producirse un desgaste tan intenso que hiciera imposible mantener una continuidad de experiencias empáticas en el tiempo.

\section{CONCLUSIONES}

La relevancia de la vida y la obra de Edith Stein para su estudio en las ciencias de la enfermería, puede resumirse en los siguientes apartados:

1.- La búsqueda incansable de la verdad, objetivo que la acompañó toda su vida.

2.- El valor de la amistad y la entrega de su persona a los demás a través de la misma.

3.- El amor a la vida, al conocimiento y al ser humano, como grandes motivaciones impulsoras de su existencia.

4.- $\mathrm{Su}$ entrega personal a los enfermos y el entusiasmo impreso en las tareas de cuidar.

5.- La búsqueda del ser humano y de su genuina interrelación, a través de la investigación fenomenológica de la empatía.

\section{BIBLIOGRAFÍA ESPECÍFICA}

- BATZDORF, Susanne M. (2001) Mi tía Edith. Ed. Espiritualidad. Madrid.

- POSELT. (2004) Madre Teresa Renata del E. S.- Edith Stein. Una gran mujer de nuestro siglo. Ed. Monte Carmelo. Burgos. - STEIN, Edith (2002) Escritos autobiográficos. Obras Completas, I. Ediciones El Carmen; Ed. Monte Carmelo; Ed. Espiritualidad. Burgos, pp. 119-128

- STEIN, Edith. (1998)- cartas a Roman Ingarden (1917-1938). Ed. Espiritualidad. Madrid.

- STEIN, Edith.(2002) Escritos autobiográficos. Obras Completas, I. Cartas. Ediciones El Carmen; Ed. Monte Carmelo; Ed. Espiritualidad. Burgos, pp. 551-678

- STEIN, Edith (2002) Escritos autobiográficos. Obras Completas, I. Servicio en el Hospital Militar de MährischWeibkirchen. Ediciones El Carmen; Ed. Monte Carmelo; Ed. Espiritualidad. Burgos, pp. 415-453.

- STEIN, Edith (2004). Sobre el problema de la empatía. Ed Trotta. Madrid.

\section{BIBLIOGRAFIA GENERAL}

- Del Pozo Abejón, Gerardo (2006) Edith Stein y los místicos españoles. Facultad de Teología San Dámaso. Madrid. 
- De Meester, Conrad (2005) Santa Edith Stein. Monte Carmelo. Burgos.

- Feldmann, Christian (1999) Edith Stein judía, filósofa y Carmelita. Herder. Barcelona.

- García, Ciro (2000) Edith Stein o la búsqueda de la verdad. Monte Carmelo, Burgos.

- García Rojo, Ezequiel (2002).- Una mujer ante la verdad. E. Espiritualidad. Madrid.

- García Rojo, Ezequiel (1998) Edith Stein. Existencia y pensamiento. E. Espiritualidad. Madrid.

- García Muñoz, Florencio (2007) Benedicta de la Cruz. Edith Stein signo de contradicción. San Pablo, Madrid.

- Ochayta, Félix (1998) Edith Stein, nuestra hermana. Monte Carmelo, Burgos.

- Ranff, Viki (2005) Edith Stein en busca de la verdad. Ediciones Palabra, Madrid.

- Rosales Meana, Diego Ignacio (2006) Irreductibilidad de la vida humana según la empatía. Universidad Panamericana, México.

- Sancho Fermín, Fco. Javier (1998) Edith Stein. Pensamiento y paisaje. Monte Carmelo. Burgos.

- Sancho Fermín, Fco (1998) Las páginas más bellas de Edith Stein. Monte Carmelo. Burgos.

- Sancho Fermín, Fco (1999) Edith Stein. Tren hacia Auschwitz. Monte Carmelo. Burgos.

- Steinh, Edith (2004) Obras Completas II. Escritos filosóficos. Etapa fenomenológica 1915-1920. Monte Carmelo. Burgos.

- Stein, Edith (2002) Obras Completas III. Escritos filosóficos. Monte Carmelo.
- Stein, Edith (2003) Obras Completas IV. Escritos antropológicos y pedagógicos. Monte Carmelo.

- Stein, Edith (2004) Obras Completas V. Escritos espirituales. Monte Carmelo.

- Stein, Edith (1997) Autorretrato epistolar, 1916-1942. E. Espiritualidad. Madrid.

- Stein, Edith (2001) La mujer. Ediciones Palabra. Madrid.

- Stein, Edith (1998) Los caminos del silencio interior. Espiritualidad, Madrid.

- Stein, Edith (2001) Cómo llegué al Carmelo de Colonia.Monte Carmelo, Burgos.

- Stein, Edith (2001) Pensamientos. Monte Carmelo, Burgos.

- Stein, Edith (2003) La estructura de la persona humana. Biblioteca de Autores Cristianos, Madrid.

- Stein, Edith (2000) Ser finito y ser eterno.- Monte Carmelo, Burgos.

- Stein, Edith (2000) La Ciencia de la Cruz. Monte Carmelo, Burgos.

- Stein, Edith (2005) Excurso sobre el idealismo trascendental.Ediciones Encuentro, Madrid.

- Stein, Edith (2004) Sobre el problema de la empatía. Trotta, Madrid.

- Stubbermann, Claire Maria (2003) La mujer en Edith Stein: antropología y espiritualidad. Facultad de Teología del Norte de España. Burgos.

- Uwe Müller y Amata Neyer, María (2004) Edith Stein. Vida de una mujer extraordinaria. Monte Carmelo, Burgos.

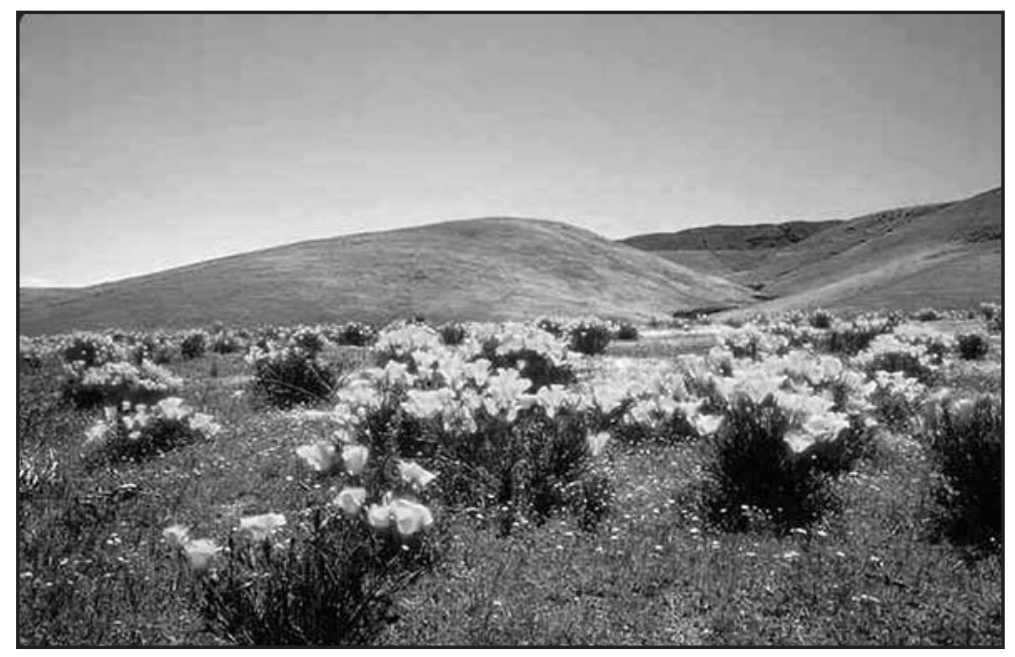

